\title{
PARA UMA CRÍTICA DA ECONOMIA LINGUÍSTICA: O APAGAMENTO DA ONTOLOGIA SOCIAL DA LÍNGUA E DO SUJEITO-FALANTE A PARTIR DE LOCKE
}

\author{
Carla Macedo Martins
}

\begin{abstract}
Resumo: Neste ensaio, analisamos a fundação da língua e do sujeito-falante a partir do Ensaio acerca do entendimento bumano, de John Locke. Nesta obra, discutimos a formulação da noção moderna de língua enquanto espaço do universal, com vistas à comunicabilidade e funcionalidade, e da noção de sujeitofalante como senhor do discurso e lócus de transformação linguística. Observa-se, assim, neste pensador, um contraponto à ontologia social da língua identificada em Marx e Engels na obra A Ideologia Alemã. O ensaio correlaciona ainda a fundação da língua e do sujeito em Locke com a política e a ciência modernas capitalistas. Por fim, o texto vincula a discussão sobre a ontologia da língua e do sujeito com as análises contemporâneas a respeito da dicotomia entre diversidade cultural e universalismo científico no ambito das ciências sociais e bumanas, e as possiveis contribuições das análises do discurso de inscrição marxista.

Palavras-chave: Ontologia. Epistemologia. Historicidade. Lingua. Universalismo.
\end{abstract}

\section{INTRODUÇÃO}

A dicotomia diversidade-universalismo constitui uma das questões epistemológicas e políticas mais candentes da atual sociabilidade capitalista. Tal polaridade se traduz, muitas vezes, por uma segunda dicotomia - culturas versus ciência - que não só tende a essencializar estas instâncias contemporâneas de produção do humano, como também contribui para reproduzir as formas de sociabilidade vigentes.

Neste sentido, Ortiz (2008), em obra recente, aborda estas dicotomias do ponto de vista do que poderíamos denominar políticas linguísticas. O autor toma, como ponto de partida, a atual hegemonia do inglês no campo das ciências sociais e humanas, em que, de forma paralela à das ciências duras, a língua anglo-saxã é considerada como a "língua de ciência", ou seja, como a língua de expressão do universal. O livro em foco evidencia como o ideário da língua universal e funcional se

\footnotetext{
*Fundação Oswaldo Cruz. Doutora em Linguística. Email: cmartins@fiocruz.br.
} 
articula, por contradição, com a valorização acrítica das chamadas línguas nacionais, ambas em funcionamento na dinâmica capitalista. Desta forma, Ortiz aponta a necessidade de problematizar a convivência contraditória entre a valorização coercitiva do padrão - como ocorre hoje através dos recursos tecnológicos da web - e a ênfase no "diferente" ou "na diversidade dos sotaques", nos termos do autor.

O presente ensaio segue a trilha crítica apontada por Ortiz, assim como sua temática. Contudo, ao invés de analisarmos o funcionamento dos discursos sobre a diversidade e o universal linguísticos na contemporaneidade, buscamos retraçar, numa espécie de uma "crítica da economia linguística", as bases econômicas e político-filosóficas da constituição desta dicotomia no âmbito do linguístico. Para tal, investigamos a produção histórica de duas noções linguísticas hoje estabelecidas: a de sujeito-falante e a de língua.

Tais noções são fundamentais, por sua vez, para a compreensão do projeto moderno de sociedade e de conhecimento e, portanto, também para a identificação de suas contradições. Em outras palavras, pretendemos indicar que a crítica em torno da oposição entre língua e sujeito-falante pode ser tecida de forma paralela, embora não em sobreposição, à crítica sobre a dicotomia culturas-ciência, característica da sociabilidade moderna burguesa.

Nossa finalidade consiste em indicar que o processo histórico de produção destas noções busca apagar sua própria historicidade, tendo como consequência ideológica a perspectiva de sujeito-falante (individual) e língua (única) como intrínsecos e constantes ao social. Naturalizam-se, assim, tanto a noção do indivíduo criador (a-histórico), quanto a do universal inexorável (igualmente a-histórico).

Tais naturalizações são centrais à constituição da política e da ciência moderna. Em termos gerais, o ensaio busca indicar o processo de gênese da noção de sujeito-falante como o espaço da criação linguística, do "sotaque", do "diverso" e da transformação (caso o espaço do social seja por demais coercitivo). O objetivo de nosso percurso no presente texto é também apontar como esta gênese se vincula a outra, que diz respeito à construção da noção de língua na modernidade. A noção hodierna de língua resulta deste mesmo processo: é o locus da regra, do social, do universal - e até do coercitivo. 
Para resgatarmos a historicidade destas duas noções, portanto, voltamo-nos para o pensamento de John Locke. No entanto, para iniciarmos nossa reflexão, comecemos de forma objetiva: com uma paródia.

\section{UMA PARÓDIA}

Estamos nos referindo ao livro Viagens de Gulliver, de subtítulo Viagens a várias nacões remotas do mundo, do irlandês Jonathan Swift (16671745). A obra consiste de uma paródia à literatura de viagens inerente à expansão mercantil-colonial europeia dos séculos anteriores, expansão acompanhada da produção e do acúmulo de conhecimentos, em função da exploração de "novos mundos".

As Viagens de Gulliver contam as visitas a quatro locais imaginários, por um narrador também ficcional, Lemuel Gulliver, cirurgião e capitão de navio. A viagem que nos interessa, em particular, é ao continente de Balnibardo. Na cidade de Lagado, capital do continente, grande como "meia Londres", só há casas em ruínas; "o povo, coberto em andrajos, andava com passos precipitados, tendo um olhar feroz". No campo, o narrador depara-se com um cenário semelhante: um povo miserável, empregando "muitas espécies de instrumentos", mas sem obter do cultivo da terra nenhum resultado. Destacam-se ilhas de prosperidade, com palácios e terra bem cultivada, que o narrador não deixa de marcar como exceção.

Dada a situação desoladora, alguns homens de negócios resolveram trazer de Laputa - uma ilha flutuante no ar, também visitada por Gulliver - as "luzes das matemáticas", para erigir as "artes" e as "ciências inferiores" de Lagado em novas bases. Esta proposta é vista com algum ceticismo por alguns grandes proprietários de terra com os quais Gulliver trava relações, embora tais proprietários não se oponham, a rigor, à proposta de importação de novos conhecimentos e métodos.

Para implantar, assim, as artes e as ciências em Lagado, os homens de negócios haviam conseguido uma "carta-patente" para a fundação de uma academia. O narrador, tendo sido "uma espécie de Projetista quando mais jovem" e sendo uma "Pessoa de muita Curiosidade e Credulidade" (SWIFT, 2010, p. 273), aceita o convite para visitá-la. 
Aqui, neste ponto da narração, figura explicitamente a "ciência", incluindo médicos, filósofos, engenheiros, enfim, todos aqueles relacionados à produção da técnica e das teorias linguísticas e políticas da modernidade na qual vive o autor. Considera-se, inclusive, que a crítica de Swift, neste e em outros trechos de referência à "ciência", tem um alvo objetivo: a Royal Society, fundada na Inglaterra em 1660, como um desdobramento da discussão em torno da obra de Francis Bacon (1561 1626), congregando, entre seus primeiros membros, Isaac Newton, John Wilkins e John Locke.

A academia é ampla e organizada em diversos cômodos. Em cada cômodo, o narrador encontra um ou mais "engenheiros", sempre descritos com tintas absurdas e extremamente cômicas:

O primeiro Homem que vi era magro, com Mãos e Rostos sujos de Fuligem, Cabelo e Barbas longos, descuidados e chamuscados em alguns lugares. Eram todas da mesma Cor Suas Roupas, sua Camisa e sua Pele. Havia oito anos vinha trabalhando num Projeto de extrair Raios de Sol de Pepinos, os quais seriam guardados em Frascos hermeticamente fechados, e usados para aquecer o Ar nos Verões mais úmidos e inclementes. Disse-me ele julgar que com mais oito anos de Trabalho seria capaz de fornecer Sol aos Jardins do Governador a Preços módicos; porém queixava-se de estar com seu estoque em baixa, e pediume que the desse algo como Incentivo ao Engenho [...]

Vi um outro ocupado em calcinar Gelo, transformando-o em Pólvora, o qual me mostrou um Tratado concernente à Flexibilidade do Fogo, que pretendia publicar.

Houve um Arquiteto mui engenhoso que inventara um novo Método de construir Casas, começando com o Telhado e descendo até chegar às Fundações, o qual ele me justificou apontando para a prática semelhante utilizada pela Abelha e a Aranha, esses dois Insetos prudentes. [...] (SWIFT, 2010, p. 274-275).

Conforme o leitor pode observar, a paródia de Swift indica o contexto histórico de emergência de alguns elementos e "mitologias" da ciência moderna, embora ainda distante do que caracterizaria seu alcance 
e sua centralidade no capitalismo contemporâneo. Na paródia, estão enfocados o absurdo e o inusitado das técnicas; a negação da práxis; o financiamento da atividade científica; a suposta alienação da ciência e do cientista; a futura indústria editorial das publicações (papers); a valorização da natureza como critério de verdade; e ainda outras questões que um leitor mais imaginativo pode aventar.

A língua (da ciência), como não poderia deixar de ser, é também objeto de sátira, quando Gulliver adentra a Escola de Línguas:

Fomos à Escola de Línguas, onde três professores estavam reunidos com o fim de melhorar o Idioma de seu País. ${ }^{1}$

O primeiro Projeto consistia em encurtar o Discurso, reduzindo os Polissílabos a uma Sílaba apenas, e eliminar os Verbos e Particípios, pois que na realidade todas a coisas imagináveis não são senão Substantivos.

Outro Projeto era um Plano de abolir toda e qualquer Palavra; e esse Plano era defendido como uma grande Vantagem para a Saúde tanto quanto para a Brevidade. Pois claro está que cada Palavra que dizemos corresponde em certo grau a uma Diminuição de nossos Pulmões causada pela Corrosão e, conseqüentemente contribui para encurtar as nossas Vidas. Assim, propunha-se que como as Palavras não eram senão nomes de Coisas, mais conveniente seria que todos os Homens levassem consigo as Coisas necessárias para expressar os Negócios específicos sobre os quais haviam de falar. E essa Invenção teria certamente sido adotada, grandemente facilitando a Vida e melhorando a Saúde dos Súditos, se as Mulheres, unidas à Gentalha e aos Analfabetos, não tivessem ameaçado se rebelar, a menos que thes dessem a liberdade de falar com suas línguas, tal como faziam seus antepassados; o que mostra o quanto são Inimigas Inconciliáveis da Ciência as Pessoas Comuns. Contudo, muitos dos mais Sábios e Doutos seguem este novo Plano de se exprimir por meio de Coisas, o qual tem uma única Inconveniência, que é a de que, quando se tem negócios muito

\footnotetext{
${ }^{1}$ Ver notas a esta edição da obra: "A Real Sociedade nomeou uma comissão com este fim, mas esse era um assunto sobre o qual muitos escritores fizeram propostas, inclusive o próprio Swift, autor de A proposal for correcting, improving and ascertaining the English tongue, in a letter to the Earl of Oxford' (SWIFT, 2010, p. 422).
}

MARTINS - Para uma crítica da economia linguística... 
amplos e diversos, torna-se preciso levar muitas Coisas nas Costas, a menos que se possa pagar um ou dois Criados fortes para ajudar. [...] [Dois destes Sábios] quando se encontravam nas Ruas, depunham no Chão seus Fardos, abriam os Sacos e conversavam por uma hora $[\ldots]$.

Outra grande Vantagem proposta por esta Invenção é que serviria como Língua Universal a ser compreendida por todas as Nações civilizadas, cujos Produtos e Utensílios são de modo geral da mesma espécie, ou bem semelhantes, de modo que seus Usos podem ser facilmente entendidos. $\mathrm{E}$ assim poderiam os Embaixadores tratar com Príncipes ou Ministros de Estado estrangeiro cujas Línguas desconhecessem por completo. (SWIFT, 2010, p. 279-282, grifos no original)

Em primeiro lugar, o trecho satiriza a concepção de que seria desejável a "justa" correlação entre "nomes" (se possível, monossilábicos) e "coisas", a ser elaborada por especialistas, que eliminariam, portanto, a polissemia da língua. Como a "língua" parece resistir a este projeto, que se eliminem as palavras, então, em sua inelutável polissemia, mesmo que com a resistência dos falantes a estes importantes avanços científicos...

Em segundo lugar, o trecho ridiculariza o ideal da Língua Universal, no seu pressuposto de que a multiplicidade de línguas é algo a ser combatido. A diversidade linguística, para estes "sábios", imporia tarefas para tratar das questões que o capitalismo nascente e corrente descreveria como "úteis" e "produtivas" - como o comércio entre as nações.

Em terceiro lugar, nesta visita, além da crítica à ciência nos aspectos já elencados acima em relação à visita anterior, é sugerida ainda uma relação entre estes programas de formatação de uma língua universal e a sociedade cindida em classes sociais, já que são inimigas da ciência as "Pessoas Comuns", nomeadamente mulheres e analfabetos.

Iniciamos nosso ensaio com a lembrança de Swift porque esta constitui uma expressão do nascimento da modernidade linguística, em suas facetas ontológicas e epistemológicas, sendo condicionada, assim, por questões de natureza política. Não à toa, por fim, Gulliver acaba 
indo, de fato, à escola de Projetistas Políticos - cuja insensatez, a propósito, o deixa "melancólico" (SWIFT, 2010, p. 282).

Mas deixemos esta visita de lado, porque cumpre agora aprofundar nossa discussão para além - ou para aquém - da paródia de Swift. John Locke, um contemporâneo e conterrâneo de Swift, e um teórico da "língua" e das "Coisas", é o foco de nossa análise no presente ensaio.

\section{MODERNIDADE LINGUÍSTICA EM LOCKE}

Inicialmente, cabe observar que a discussão sobre a linguagem apropriada para a ciência e a política não é exclusiva da obra de Locke. Tornar a língua segura, límpida e transparente para a ciência e para a política (modernas e burguesas) é um objetivo constante da história das reflexões filosóficas sobre a linguagem. Nas palavras de Auroux (1998), "desde Francis Bacon e John Locke até Carnap, passando por Leibniz e Condillac, numerosos são os filósofos que denunciaram o abuso das palavras [...]" (p. 209).

Este projeto, ao mesmo tempo político, linguístico e científico, permanece nos séculos XIX e XX, embora com mutações relativas às sucessivas necessidades do projeto de sociabilidade capitalista (por exemplo, no século XIX, a busca de perfeição ontológica da língua se desloca para a de funcionalidade comunicativa, legitimando a preponderância atual da língua inglesa na esfera científica, de acordo com Ortiz (2008)).

No entanto, a despeito desta extensa literatura, coube a Locke, de fato, um papel de destaque. À formulação da política e da ciência modernas, Locke agrega uma discussão ontológica e epistemológica sobre a "língua" que tem como consequência a própria fundação deste objeto. Embora não seja pioneiro em tematizar a questão da língua como obstáculo para a modernidade e o progresso (referir-se, por exemplo, a Francis Bacon), Locke buscou superar os supostos "limites" da língua, buscando formatá-la para "uso" pela sociabilidade burguesa. 
Por estas razões, para analisar a historicidade das noções de língua e sujeito-falante, devemos remontar a John Locke ${ }^{2}$. Sua obra Ensaio acerca do entendimento humano, sobretudo o Livro III, intitulado "Palavras", constitui um documento fundamental da epistemologia e da reflexão linguística, pois coloca como um de seus objetivos exatamente tornar a língua e o conhecimento funcionais para a ciência e para a sociedade. Se, para Locke, governar e produzir conhecimento cabe às classes proprietárias, a estas mesmas classes cabe gerir a língua de uma forma adequada a estes fins. E é neste ponto que se inicia nossa discussão linguística na obra de Locke.

O desafio de gerir a língua é diretamente abordado pelo autor na "Carta ao leitor", que serve de prefácio à obra. Neste, Locke se coloca, diferentemente de Boyle ou Newton, como um "trabalhador inferior da ciência", que "remove parte do entulho que está no caminho do conhecimento". O "entulho" a que Locke se refere são os "abusos da linguagem" no campo da filosofia. No original, o texto segue nos seguintes termos:

Certamente, o mundo estaria muito mais adiantado se o esforço de homens engenhosos e perspicazes não estivesse tão embaraçado pela erudição e pelo uso frívolo de termos desconhecidos, afetados e ininteligíveis, introduzidos nas ciências, e fazendo disso uma arte a tal ponto de a filosofia, que nada mais é que o verdadeiro conhecimento das coisas, tornar-se imprópria ou incapaz de ser apreciada pela sociedade mais refinada e nas conversas eruditas. Formas vagas e sem significado de falar, e abuso da linguagem, têm por muito tempo passado por mistérios da ciência; palavras difíceis e mal empregadas, com pouco ou nenhum sentido, têm, por prescrição, tal direito que são confundidas com o pensamento profundo e o cume da especulação, sendo difícil persuadir não só os que falam como os que os ouvem que são apenas abrigos da ignorância e obstáculos

\footnotetext{
${ }^{2} \mathrm{O}$ reconhecimento de Locke como um dos fundadores do projeto de modernidade linguistica é relativamente recente. Sobre esta questão, podemos citar apenas o trabalho de Bauman e Briggs (2003), já mencionado. Este tem como objetivo discutir como a obra de Locke produz uma noção de língua instrumental para a ciência e a política modernas, contribuindo para estabelecer o ideal de universalismo linguístico. O presente ensaio segue uma linha de reflexão distinta, embora não oposta, da de Bauman e Briggs, na medida em que pretende colocar em tela a historicidade das noções de língua e sujeito-falante, ou seja, uma ontologia do linguístico.
} 
ao verdadeiro conhecimento. [...] Espero, pois, ser perdoado se tratei longamente deste assunto no Livro Terceiro, em que tentei fazê-lo de modo simples, para que nem o radicalismo do dano, nem o predomínio do costume, sejam desculpas aos que não se preocupam com o significado de suas próprias palavras e não empreendem uma pesquisa sobre o significado de suas expressões. (LOCKE, 1973, p. 143)

Neste trecho, observamos a tematização do "abuso da linguagem", identificado como um obstáculo ao "verdadeiro conhecimento das coisas" - questão a que se resume, afinal, a filosofia, segundo Locke. Isso implica em refletir sobre a língua, mesmo que por conta de seus limites, possibilitando-lhe um espaço na (nova) produção do conhecimento e da política e apontando também, por consequência, para a necessidade da regulação da língua e dos "sujeitos-falantes".

Destaque-se, ainda neste trecho, que o leitor como indivíduo é chamado a empreender esforços para superar o problema, passando a se preocupar com o "significado de suas próprias palavras" e com "O significado de suas expressões". Este sujeito é "senhor" de suas "próprias" palavras - embora precise "medi-las", já que se encontra submetido, nos termos de Locke, à necessidade do consentimento para a vida em sociedade.

Língua e sujeito-falante estão, portanto, mapeados neste trecho. Passemos a discuti-los de forma mais aprofundada em outros pontos desta obra de Locke. Cumpre observar que nossa separação, para os fins desta discussão, entre língua e sujeito-falante tem como objetivo apenas tornar nosso percurso mais claro. Reiteramos que nossa perspectiva é que as duas noções se fundam nos mesmos processos históricos.

\section{A LÍNGUA EM LOCKE}

Em linhas gerais, na obra de Locke, a origem da língua se dá na relação entre mente, indivíduo e natureza; posteriormente a esta gênese, cabe a alguns indivíduos controlar e aperfeiçoar a língua; o sentido deste aperfeiçoamento está definido pela necessidade de simplificação, funcionalidade e inteligibilidade. 
A língua e as ideias como objetos específicos se encontram, por exemplo, na discriminação dos campos de conhecimento, apresentados, de forma resumida, no último parágrafo da obra. Vejamos a citação:

Um homem pode empregar seus pensamentos acerca de nada, mas também na contemplação das próprias coisas, para a descoberta da verdade; ou acerca de coisas em seu próprio poder, que são suas próprias ações, para obtenção de seus próprios objetivos, ou nos sinais de que a mente faz uso de ambos em um ou em outro, e na correta ordenação deles, para sua mais clara informação. Todas estas três, a saber, coisas, como elas são em si mesmas cognoscíveis; açoes, como elas dependem de nós, com vistas à felicidade; e o uso correto de sinais com vistas ao conhecimento; sendo toto coelo diferentes, parecem-me ser as três grandes províncias do mundo intelectual, totalmente separadas e distintas entre si. (LOCKE, 1973, p. 350, grifos no original)

Cada um destes objetos derivaria também ciências diferenciadas: primeiro, o conhecimento das coisas, como elas são em seus próprios seres, suas constituições, propriedades e operações, objeto da Física ou Filosofia Natural; segundo, "a perícia de aplicar corretamente nossos poderes e ações para obtenção de coisas boas e úteis", estudada pela Prática ou, mais precisamente, pela Ética; terceiro, os sinais, criando um campo de estudos semióticos e lógicos (Cap. IV, XXI, p. 349).

Cabe observar que esta última disciplina não se refere apenas às palavras, mas também às ideias que o espírito produz a respeito das coisas; as palavras registram tais ideias e as tornam públicas. Locke aponta, desta forma, tanto para um campo de estudos da representação as "ideias", discutidas no livro II da obra mencionada - quanto da significação - as "palavras", abordadas no livro III da mesma obra mantendo, contudo, as ideias claras e distintas como a base do conhecimento.

Por consequência, o destaque dado à língua se vincula, em Locke, à produção de ideias precisas, a partir do entendimento das coisas sensíveis e da criação de termos gerais, com o objetivo de comunicar com clareza e rapidez. A vinculação entre ideias e língua é que fornecerá 
a esta última a possibilidade de manter relações estáveis e sólidas entre sentidos e sons, possibilidade que, portanto, a tornaria um instrumento confiável para a ciência e a política. É inevitável a passagem pela língua, já que há uma relação muito estreita e constante entre ideias e palavras. Assim, mesmo que de forma "conflituosa", pois a língua é também fonte de distorção, Locke delimita um campo de conhecimento em que figura a especificidade deste novo objeto ("língua").

A língua como uma produção humana diferenciada de outros "sinais" da natureza nos parece evidente hoje, imersos que estamos nas concepções modernas de "língua" (e de "humano"). Contudo, para a semiologia medieval, o signo linguístico é apenas um símbolo entre outros. Na Idade Média, todo o universo é significante, ou seja, o mundo todo é formado por sinais da voz de Deus. Ou, nas palavras de Biard (1989, apud AUROUX, 1998, p. 100), a linguagem se inscreve em "uma visão cosmo-teológica em que Deus é fala e em que todo resto é signo" 3 .

$\mathrm{O}$ estatuto da linguagem em Locke é completamente distinto. $\mathrm{O}$ signo linguístico deixa de ser um símbolo entre outros, para se tornar um modelo de "significação". Ou seja, qualquer que tenha sido a contribuição dos medievais sobre a questão do signo linguístico, é a teoria política e epistemológica encarnada pela obra de Locke que estabelece um dos eixos fundamentais de nossas concepções hodiernas sobre a língua.

Aqui cabe retomar, em linhas muito gerais, a revolução cartesiana sobre o entendimento, para estabelecer mais amplamente a relação entre a fundação das teorias modernas do conhecimento e formulação de um objeto denominado "língua". Ao fazer do conhecimento pelo homem o próprio objeto, Descartes estabelece que o espírito e a matéria não são da mesma natureza ontológica. A representação deixa de ser, definitivamente, da mesma natureza daquilo que ela representa. Como dirá Spinoza (1632-1677), por volta do mesmo período, “a ideia do círculo não é redonda" (apud AUROUX, 1998).

Afirma-se, assim, a tríade "coisa-ideia-som", que será, nas reflexões sobre a língua a partir desse momento, trabalhada e retrabalhada em diferentes direções. A "ideia” não é mais, de forma

\footnotetext{
${ }^{3}$ Lembramos aqui a análise semelhante de Foucault, sobre a transição do período renascentista para o moderno, em As palavras e as coisas (1999).
}

MARTINS - Para uma crítica da economia linguística... 
alguma, uma "coisa do mundo". Neste contexto, a língua passa a ser considerada "arbitrária" ou "convencional", em dois sentidos.

Em primeiro lugar, a relação entre coisas do mundo, ideias e sons da língua não se baseia em nenhuma identidade ou semelhança entre si; assim, o signo não se assemelha à sua significação. Em segundo lugar, a origem também é uma "convenção": a língua só existe em função da ação humana (individual ou consensual em dado grupo humano) ou da própria existência humana; ou seja, a significação do signo é instituída pelo homem (em sociedade).

A linguagem - e o pensamento - passam a ser, de fato, uma "linguagem mental", isto é, um conjunto de signos criado pelo homem. Esta revolução tem consequências profundas na modernidade, inclusive na contemporânea. Nas palavras de Auroux (p. 102, 1998), “o pensamento-linguagem dos homens ocupa toda a ordem do simbólico”, ocorrendo, neste processo, o que podemos chamar de uma "digitalização" do espírito, em oposição a um pensamento "analógico" (em relação às coisas da natureza).

Portanto, Locke foi o primeiro pensador moderno que aprofundou as consequências epistemológicas desta "digitalização do espírito" para o campo da língua: assim como o pensamento é "arbitrário", a língua dita "natural" também o é. Além disso, ao mesmo tempo, Locke contribui para a elaboração de uma teoria do conhecimento e de uma filosofia política na qual o signo linguístico (arbitrário) deixa de ser um símbolo ao lado de outros, para se afirmar como instrumento central da ciência e da política.

Neste sentido, desenvolveremos uma abordagem da fundação do objeto "língua" por Locke analisando como este autor constrói, de um lado, uma teoria sobre a origem e o papel da língua e, de outro lado, uma concepção sobre a arbitrariedade do signo linguístico. Voltando ao texto de Locke,

O homem é equipado para formar sons articulados. Deus, tendo designado o homem como criatura sociável, não o fez apenas com inclinação e necessidade para estabelecer camaradagem com os de sua própria espécie, mas o forneceu também com a linguagem, que passou a ser o instrumento mais notável e o laço comum da sociedade. [...] 
É preciso que se transformem em sinais de ideias. Além de sons articulados, portanto, foi mais tarde necessário que o homem pudesse ter a habilidade para usar esses sons como sinais de concepções internas, e fazê-los significar as marcas das ideias internas de sua própria mente, pelas quais elas serão conhecidas pelos outros, e os pensamentos das mentes dos homens serão mutuamente transmitidos.

Formar sinais gerais deles. Mas nem isso foi suficiente para formar palavras tão úteis como elas devem ser. Não basta, para a perfeição da linguagem, que os sons possam ser transformados em sinais de ideias, a menos que estes sinais possam ser usados para compreender várias coisas particulares. [...] Para remediar este inconveniente, a linguagem passou por outro aperfeiçoamento pelo uso de termos gerais, pelos quais uma palavra era formada para indicar uma multidão de existências particulares [...]. (LOCKE, 1973, p. 227)

Locke, neste segmento, explica a origem da língua a partir da capacidade humana de produzir sons articulados, de vinculá-los às ideias internas de cada mente, de compartilhá-los com os outros, e de generalizar seu uso para designar "várias coisas particulares". Observe-se que a sequência deste processo indica uma equivalência entre "língua" e "palavra", esta última como sinais de "ideias".

Reiterando, a palavra seria arbitrária em duas dimensões: primeiro, na associação entre palavras e ideias; segundo, na prevalência de determinadas associações em detrimento de outras, como resultantes da decisão consensual, ou convencional, ou, ainda, nos termos da filosofia política de Locke, do consentimento (entre os falantes).

Ainda sobre a arbitrariedade da língua, remetemo-nos ao seguinte trecho:

Seu significado [da palavra], perfeitamente arbitrário, não é consequência de uma conexão natural. Palavras, pelo longo e familiar uso, como foi dito, estimulam nos homens certas ideias tão constantes e prontamente que estes são aptos para supor uma conexão natural entre elas. É evidente, porém, que elas denotam apenas ideias peculiares dos homens, e por uma perfeita imposição 
arbitrária, pois elas freqüentemente deixam de estimular em outros (mesmo se usam a mesma língua) as mesmas ideias que nós consideramos como seus sinais; e todo o homem tem liberdade tão inviolável para formar palavras para significar ideias do seu agrado como ninguém tem o poder para obrigar outros a ter as mesmas ideias em mente quando, como ele, usam as mesmas palavras. $\mathrm{Na}$ verdade, o uso comum, de tácito acordo, atribui certos sons a certas ideias em todas as linguagens [...] a menos que as palavras de uma pessoa estimulem as mesmas ideias em quem as escuta, tornando-as significativas no discurso, não fala inteligivelmente. (LOCKE, 1973, p. 231, grifo no original)

Portanto, para Locke, a relação entre palavras e ideias não é natural, embora o uso constante da língua possa levar a tal suposição. As palavras são convencionadas pelo "uso", apesar de o indivíduo possuir plena liberdade na sua produção.

Ainda no trecho anterior, podemos destacar também uma primeira função primordial da língua em Locke: a comunicação, ou o intercâmbio de ideias entre os homens. A função da língua como comunicação - com a suposta necessidade de garantir a univocidade dos sinais - é uma questão central na teoria linguística de Locke.

Uma segunda função da língua seria constituir-se como um instrumento de generalização. Mesmo as ideias simples não são um reflexo das coisas, pois a ideia de uma maçã é uma abstração, diferente de qualquer conjunto de maçãs ou qualquer exemplar de maçã particular. A generalização é uma categoria do conhecimento, e não das coisas, e as palavras desempenham um papel fundamental neste processo. Generalização e abstração se dão em função da razão e da necessidade (ou da "economia" de esforços). Nas palavras de Locke,

A maioria das palavras são termos gerais. Todas as coisas que existem, sendo particulares, seria, talvez, julgado razoável que as palavras, que devem ser conformadas às coisas, deveriam ser também, quero dizer, quanto ao seu significado; não obstante, descobrimos o oposto disso. A maioria das palavras que constituem todas as linguagens são termos gerais, o que não tem sido resultado do descuido ou do acaso, mas da razão e da necessidade. (LOCKE, 1973, p. 232) 
Geral e universal são categorias do entendimento. [...] Geral e universal não comportam a existência real das coisas, mas são invenções e criaturas do entendimento, formadas por eles para seu próprio uso e se referindo apenas a sinais, quer palavras, quer ideias. (LOCKE, 1973, p. 235)

Assim, a língua teria duas funções básicas: primeira, a de simbolizar a generalização e a abstração ("ideias") em formas linguísticas ("palavras"); segunda, a de transmitir tais generalizações e abstrações entre os seres humanos em sociedade (na "comunicação" e no "uso filosófico da língua"). Ou, ainda, nos termos mais sucintos do texto lockiano, "as palavras são usadas para registrar e comunicar nossos pensamentos" (Cap. IX, p. 257).

Com o intuito de garantir o intercâmbio e clareza da língua em "uso", a produção da língua deve ser regulada. A esta tarefa, Locke dedica três capítulos do Livro III, intitulados "Imperfeição das palavras", "O abuso das palavras" e "Remédios para abusos e imperfeições anteriores". Em resumo, tais capítulos buscam garantir, por um lado, univocidade e transparência entre palavra e ideia e, por outro lado, clareza e rapidez da sinalização da ideia pela palavra. No texto original,

Quem tem nomes sem ideias, suas palavras carecem de sentido e fala apenas através de sons vazios. Quem tem ideias complexas em seus devidos nomes encontra-se sem liberdade e rapidez em suas expressões, sendo obrigado a usar perífrases. Quem usa palavras descuidada e irregularmente não será levado em consideração ou entendido. Quem aplica seus nomes para ideias de modo diverso do uso ordinário carece de propriedade em sua linguagem e fala algaravia. E quem tem ideias de substâncias discordantes com a existência real das coisas carece dos materiais do verdadeiro conhecimento em seu entendimento, tendo em lugar disso apenas quimeras. (LOCKE, 1973, p. 265)

A necessidade destas regulações se origina da natureza eminentemente polissêmica - como sinônimo de imperfeita - do signo linguístico. A origem da polissemia, por sua vez, se vincula, por coerência, ao próprio dinamismo da produção das ideias pelo indivíduo e às dificuldades do processo de significação na relação com as coisas da natureza. 


\section{O SUJEITO-FALANTE EM LOCKE}

Conforme apresentamos até aqui, a origem, a função e a natureza da língua em Locke a colocam em uma dimensão específica humana do "entendimento" e do intercâmbio: a língua se relaciona às ideias, cuja produção, por sua vez, constitui uma liberdade inalienável do indivíduo a ser negociada quando este se encontra em sociedade.

Assim, Locke, ao explicar a língua como uma dimensão humana, fruto de suas relações com o sensível e com o propósito de comunicar, contribui para instaurar, no âmbito moderno, a língua como um objeto passível de estudo e regulação, e cada indivíduo - em potencial - como sujeito-falante. É exatamente para a fundação do indivíduo-sujeitofalante que nos voltamos neste item.

Reiteramos que, em Locke, se a produção das ideias é livre e individual, a produção das palavras também o é. Retomamos o trecho já citado acima: "todo o homem tem liberdade tão inviolável para formar palavras para significar ideias do seu agrado como ninguém tem o poder para obrigar outros a ter as mesmas ideias em mente quando, como ele, usam as mesmas palavras" (Cap. II, p. 231).

Destacamos ainda outro trecho mais enfático, tanto sobre a liberdade individual, quanto sobre a necessidade de intercâmbio social:

A mesma liberdade facultada a Adão para anexar qualquer nome novo a qualquer ideia revela-se em qualquer um no presente [...]; mas apenas com esta diferença: em lugares em que os homens em sociedade já estabeleceram uma linguagem entre eles, os significados das palavras estão muito difundidos e espalhados para serem alterados. Porque os homens já se encontram providos de nomes para suas ideias, e o uso ordinário tem apropriado nomes conhecidos para certas ideias, consistindo o mau emprego dos mesmos em algo muito ridículo. [...] Mas, em comunicação com os outros, é necessário que conformemos as ideias que formamos com as palavras vulgares enunciadas por qualquer linguagem com seus conhecidos e próprios significados [...] ou também para tornar conhecido o novo significado que a elas nós aplicamos. (LOCKE, 1973, p. 254). 
É importante destacar ainda que a exclusão do contexto histórico por Locke tem como um de seus principais alvos o que poderíamos denominar, em termos linguísticos contemporâneos, "intertextualidade", ou seja, a ideia de que o sentido é produzido historicamente pela relação entre os textos. Para Locke, qualquer referência ou citação de outros textos é indício de falsidade da argumentação e, portanto, também do conhecimento (BAUMAN; BRIGGS, 2003).

Esta concepção se identifica, de forma explícita, na "Carta ao leitor". No texto original, Locke inicia sua obra nos seguintes termos:

Leitor,

Coloco em suas mãos o que tem sido o passatempo de algumas de minhas horas mais ociosas e difíceis. [...] Trata-se, portanto, leitor, do entretenimento de quem liberou seus próprios pensamentos e os foi registrando à medida que escrevia, não the cabendo invejar-me, pois lhe ofereço oportunidade para divertimento semelhante, se à medida que for lendo recorrer aos seus próprios pensamentos. É a eles, se lhes são próprios, que me refiro; mas se dependerem da crença de outrem, deixa de ser importante saber o que são, pois não decorrem da verdade mas de alguma consideração mais desprezível, e não vale a pena se preocupar com o que disse ou pensa quem diz ou pensa tãosomente de acordo com a orientação de outrem. [...] (LOCKE, 1973, p. 141)

Portanto, o verdadeiro conhecimento e o verdadeiro uso da língua em sociedade exigiria, para Locke, homens "livres", capazes de produzir "sua própria" fala ou "seu próprio" texto, independente dos condicionamentos de outras falas ou outros textos (produzidos por outros indivíduos, no caso). Como a língua não se explica pela relação entre os homens e deste com a natureza, a língua acaba sendo fruto da vontade de um sujeito livre individual - que, assim como "conhece", também "fala". Este indivíduo é também senhor de seu "discurso", pois a relação de sua fala com outras falas seria indício de sua não liberdade.

Cabe destaque aqui a discussão sobre as "palavras morais". Estas não estariam imersas na produção histórica das relações sociais, mas sim nas esferas das ideias construídas pelo indivíduo, ao "bel-prazer" da 
mente e do discurso individual, sendo impossível seu rebatimento com as "coisas". No texto:

Os nomes dados pelos homens a ideias muito compostas, tais como são em grande parte as palavras morais, têm raramente em dois homens o mesmo significado, desde que a ideia complexa de um homem raramente concorda com a de outro e freqüentemente difere da sua própria, da que tinha ontem, ou terá amanhã. (LOCKE, 1973, p. 258)

Elas são ideias reunidas ao bel prazer da mente, seguindo os próprios objetivos do discurso e seguidas por suas próprias noções; por meio do qual não se designa para copiar nenhuma coisa realmente existente, mas para denominar e classificar coisas concordantes com esses arquétipos e formas por ela estabelecidos. (LOCKE, 1973, p. 259)

\section{PARA UMA CRÍTICA DA ECONOMIA LINGUÍSTICA EM LOCKE}

Apresentada a teoria linguística de Locke, passamos à sua análise. Nosso objetivo, a partir deste ponto do ensaio, consiste em demonstrar, na mesma obra, dois processos ideológicos inter-relacionados, ambos condicionados pela produção da totalidade do social no contexto de emergência do capitalismo.

O primeiro estabelece uma relação, necessária e intrínseca, entre "falante senhor da língua", "indivíduo livre" e "sujeito de conhecimento". Por um lado, esta relação de equivalência contribui para restringir - com a mediação da língua - o político e o epistemológico à esfera individual, nos termos da sociabilidade ora nascente. Por outro lado, a fundação do simbólico também fica destituída do social, por se configurar como apriorística ao mesmo.

Fica evidente que, para Locke, na base de todo ato de linguagem há a liberdade inviolável de cada indivíduo. Isto configura o que Auroux chama de "liberalismo linguístico": para Locke, "a criatividade linguística é sempre um ato contingente da vontade individual que dá origem à linguagem" (p. 116). Por coerência, a submissão ao poder político e os 
sentidos das "suas próprias" palavras dependem, ambos, de consentimento do indivíduo. Ainda para Locke, "consentir tacitamente o uso linguístico é simplesmente aceitar que certos sons possam valer por nossas ideias e pelo que supomos ser as dos outros com relação aos mesmos objetos" (AUROUX, 1998, p. 118). Portanto, podemos afirmar que o que se denomina "liberalismo linguístico" em Locke constitui uma evidência da correlação entre sua epistemologia, sua filosofia linguística e a sua filosofia política.

Observe-se que está em questão aqui não só a noção de "sujeitofalante", mas também a de "língua". Esta também se afirma como um objeto a priori à história, se esta for compreendida como a instituição da relação dos seres humanos com natureza e também da relação dos seres humanos entre si através do trabalho (MARX; ENGELS, 2007).

A língua se vincula, para Locke, ao domínio das ideias, e só a posteriori ela se torna social. Neste processo, quando a língua seria supostamente mergulhada no social, é que se criam os equívocos e a polissemia. Assim, da mesma forma que o social é quase que uma contingência diante do livre desenvolvimento da vida individual - o que exige se teorizar filosófica e politicamente sobre o "consentimento" - a consideração da fala dos outros também o é.

No caso da língua, o social contingente impõe uma tolerância à fala dos outros, para que a língua, após o que seria o seu ingresso na comunicação, possa continuar a servir como instrumento do pensamento. Isso porque a inserção inevitável da língua nas relações sociais concretas - extrínsecas, para ele, ao ato de criação linguística geraria ainda mais problemas. Estes problemas devem ser sanados tanto com o controle individual de falante sobre sua produção linguística, quanto com o consentimento livre de cada homem em aceitar sentidos já existentes e evidenciar e negociar - sempre individualmente - sentidos (ainda) não prevalentes.

O segundo processo ideológico consiste, em outras palavras, no apagamento da ontologia social da língua, cerne da discussão marxista sobre língua e linguagem, em contraponto com a teoria linguística lockiana. Para Marx e Engels (2007), em citação bastante conhecida, 
[A consciência] não é, desde o início, consciência 'pura'. O 'espírito' sofre, desde o início, a maldição de estar 'contaminado' pela matéria, que, aqui, se manifesta sob a forma de camadas de ar em movimento, de sons, em suma, sob a forma de linguagem. A linguagem é tão antiga quanto a consciência - a linguagem é a consciência real, prática que existe para os outros homens e que, portanto, também existe para mim mesmo; e a linguagem nasce, tal como a consciência, do carecimento, da necessidade de intercâmbio com outros homens. Desde o início, portanto, a consciência já é um produto social e continuará sendo enquanto existirem homens. (MARX; ENGELS, 2007, p. 34-35)

Nos limites deste ensaio, não caberia discutir em profundidade a ontologia da língua e do sujeito propostos pela obra marxiana. Nossa referência à Ideologia Alemã aqui tem como propósito apontar a referência da ontologia do ser social marxiana que tem como um dos seus eixos a questão da linguagem fundada pelo trabalho, conforme será desenvolvido posteriormente pela obra de Lukács ${ }^{4}$.

Voltando-nos, mais uma vez, para Locke, este apagamento da ontologia social da língua explica por que a "imperfeição" e seus "remédios" são um problema central em suas discussões linguísticas. Como as palavras têm como função desempenhar o papel de sinais nas generalizações e abstrações produzidas no ato de conhecer, uma "boa" língua inevitavelmente deveria manter o vínculo entre ideias e palavras o que nem sempre ocorre, quando a língua se "contamina" pelas relações sociais.

"Equívocos" são resultantes do (mau) uso da língua em sociedade e do processo linguístico-histórico de significação. Portanto, o ato de comunicação claro e límpido pode ser alcançado apenas se nos basearmos naquilo que constituiria um controle da significação ideal e individual: tal controle geraria uma significação livre de equívocos e das imposições sociais.

Ainda para Locke, a polissemia é fruto do abuso da língua - ou da produção e do uso individual da língua. Como outros "abusos” que se

4 Para uma discussão da obra lukacsiana no diálogo com a Análise do Discurso, ver Magalhães (2003), Amaral (2008), Florêncio (2009), e Magalhães e Mariani (2010), entre outros. 
originariam na ação dos "indivíduos", a polissemia deve ser regulada e controlada por uma instância política que defenderia o "bem comum" e a própria possibilidade da "vida em sociedade" (quando antagônicos aos "interesses individuais").

Em outras palavras, a criação livre de signos pela mente seguiria a seguinte premissa: deveria haver uma correspondência unívoca - isto é, um a um - entre som e sentido. Ou seja, controlar o abuso linguístico é manter a ligação constante entre palavras e qualidades sensíveis ou conformar os nomes às coisas "tais como elas são". O saber das coisas as ideias - é, em última instância, a salvaguarda dos enganos da língua. A referência das palavras às ideias asseguraria à língua sua realidade, sendo a univocidade uma condição de comunicação.

Ao conceber uma teoria do signo linguístico, Locke controla o "abuso linguístico" que ocorreria durante o uso da língua, para possibilitar que esta seja, de fato, a medida comum do comércio e da comunicação, e produz uma dimensão central que escapa à polissemia: esta seria a língua. É desnecessário reiterar que a ordem burguesa exige a legitimidade e estabilidade jurídica em termos do "contrato entre iguais": a "literalidade" se torna, assim, uma necessidade, neste contexto.

Embora fuja ao escopo do presente ensaio, é relevante considerar, ainda, a premissa lockiana para o alcance das ideias verdadeiras: evitar ao máximo a citação da fala de outros. A intertextualidade como materialidade constituinte da língua - o que poderíamos denominar de discurso - é apagada no texto lockiano ${ }^{5}$.

Como "sujeito" e "língua" não estão "fora" da apreensão das coisas sensíveis pela razão dentro do projeto moderno, podemos afirmar que Locke produz, de fato, uma história para a língua: a língua é uma ação humana (individual) sobre a natureza, ação que necessariamente tem que estar submetida, posteriormente, às injunções da vida em sociedade. Contudo, o sujeito e a língua estão "fora" da história, esta

\footnotetext{
${ }^{5}$ Embora nossa ênfase neste item do texto seja na ontologia da língua, cabe apontar que Locke também produz uma epistemologia. Ao excluir a intertextualidade como "verdade", a significação passa a ser enfocada como uma relação entre língua, mente e coisas. Por esta razão, Bakhtin, já no século XX, promoverá uma rediscussão epistemológica da Linguística tomando como referência exatamente o conceito de "dialogismo" e sua relação intrínseca com a ideologia, inclusive buscando estabelecer uma perspectiva distinta de uma visão individual-interacionista de sujeito (para uma discussão desta temática, embora desconsiderando questões de ordem ontológica nos termos propostos no presente texto, referir-se a Brait, 1997; e a Flores, 1998).
}

MARTINS - Para uma crítica da economia linguística... 
última enquanto a produção concomitante de formas de existência material humana e de relações sociais, incluindo as simbólicas.

O sujeito - como sinônimo de "indivíduo" - se institui independente da língua como produção coletiva que se relaciona com e dá sentido à experiência sócio-histórica; a língua, em Locke, se situa "fora" da textualidade discursiva. A história que Locke constrói para a origem da língua e do ser-falante, assim, carece de historicidade.

A língua, portanto, é instrumento social, mas não é histórica; o mesmo se pode afirmar a respeito do sujeito. Retomamos, neste ponto, explicitamente, a relação desta questão com a instituição do projeto científico moderno e com a filosofia política de Locke: a fundação do sujeito-falante como "ser livre e individual" e da língua como entidade objetiva nos termos deste pensador se vincula com a instituição do "sujeito do conhecimento" e do "indivíduo político livre" - este último só é "social" quando escolhe estar em sociedade.

Assim, "falante senhor da língua", "indivíduo livre" e "sujeito de conhecimento" se articulam na instituição da nova sociabilidade. De um lado, a língua passa a ser vista como uma entidade abstrata e a-histórica, mesmo que fruto das ações de cada falante individual na produção do conhecimento; de outro lado, o sujeito-falante se funda como aquele que "livremente" a língua (embora, em alguma medida, submetido às regras sociais e linguísticas). Sujeito, língua e discurso estão, em Locke, cindidos.

Assim como a propriedade privada, a produção da língua está separada do espaço de conflitos entre sujeitos históricos, mesmo que uma de suas funções seja "social" (comunicação entre indivíduos). Portanto, para Locke, legitimar a língua para a ordem burguesa implica limitar a sua produção histórica e, ao mesmo tempo, garantir seu papel social (como instrumento de comunicação).

"Língua" e "sujeito-falante livre" se tornam uma evidência ideológica e passam a constituir uma condição para a produção do conhecimento e da política na ordem societária. Se alguns não conseguem espaço nesta nova ordem, a justificativa está na incapacidade de se comunicar e negociar "com clareza e justeza" na esfera política.

Reiteramos que esta teoria linguística exclui a possibilidade de analisar a língua naquilo que consideraríamos a materialidade real de suas 
condições de produção histórica - ou seja, dos falantes como sujeitos histórico-sociais, dos textos como formas históricas, do discurso na articulação com a ideologia. Em termos atuais, o "discurso" não é um objeto em Locke, a despeito de considerar a língua como social; pelo contrário, a língua seria aquilo que pode ser salvo do "discurso" - fruto do social, concessão do indivíduo e obstáculo à razão.

A teoria linguística de Locke, inerente à sua epistemologia e filosofia política, está no cerne da economia e da comunicação cosmopolita, assim como da apropriação da natureza pelo capitalismo nascente. Posteriormente, o caráter não provinciano da língua é também condição para a criação de classes sociais igualmente não provincianas, para o desenvolvimento do capitalismo e, mais adiante, para a consolidação dos Estados nacionais como organização sociopolítica. Para que a língua funcione como comunicação, tanto esta concepção de língua, quanto esta noção de sujeito-falante são fundamentais.

Em última instância, a filosofia linguística de Locke naturaliza a sociedade de classes e suas formas de produzir política e ciência. Locke produz não só uma teoria sobre a língua, mas também relaciona esta teoria com uma determinada concepção da relação entre sujeito e objeto e com a produção de um conhecimento confiável e da verdade (científica). "Verdade", "universal", "regras de língua" e "univocidade do signo" passam a figurar praticamente como sinônimos, produzindo o ideal de busca de uma "língua" que garanta a clareza e certeza. Ou seja, de não confiável, Locke transforma a língua em condição de conhecimento.

Estabelecida a relação entre sujeito e social nestes termos, Locke também contribui para preparar a língua para seu estudo científico e para seu uso político na modernidade. $O$ estudo da língua pela ciência linguística, gestada ainda no século XIX, e sua regulação pelas políticas linguísticas de Estado, no fim do século XVIII, tomarão como objeto "a língua" e os "sujeitos falantes" nos termos aqui apresentados 6 .

\footnotetext{
6 Embora fuja do escopo do presente texto, não poderíamos deixar de apontar a crítica ontoepistemológica já estabelecida pela obra de Pêcheux, nos termos da dicotomia logicismosociologismo como atravessamentos da ciência linguística (sobretudo em Pêcheux, 1998; e Pêcheux e Gadet, 2004).
}

MARTINS - Para uma crítica da economia linguística... 


\section{CONSIDERAÇÕES FINAIS}

Em suma, Locke condensa alguns elementos relativos à relação entre língua, ciência e política: a obra em questão busca alçar a regulação da língua a uma questão social e econômica, cindi-la ideologicamente da produção histórica, e torná-la "confiável" para a ordem societária burguesa. Tais elementos estão na base do empreendimento moderno e do papel que a língua nele exerce.

Este processo se encaminha em duas direções: de um lado, observa-se o apagamento ideológico da relação entre esta concepção de língua e as novas formas de sociabilidade do capitalismo nascente; de outro lado, identifica-se e controla-se o uso da língua (e do sujeitofalante) nas esferas públicas e científicas. A "língua" se afirma como um elemento de legitimação da política e da sociedade de classes, tornandose um componente ideológico e instrumental na produção da sociabilidade burguesa.

Gostaríamos de concluir este texto explicitando a relevância desta discussão linguística para a totalidade da produção científica contemporânea nas Ciências Sociais e Humanas. Neste âmbito, a dinâmica das polaridades universalismo-diversidade já foi tratada por uma vasta literatura crítica, além da obra já mencionada na introdução do texto.

Tal literatura aponta, em linhas gerais, uma tendência a isolar a denominada diversidade cultural da totalidade da produção social, conforme análise de Eagleton (1998; 2005). A chamada ciência também vem sendo densamente analisada, a partir de concepções como "eurocentrismo", "ocidentalismo", "colonialidade do saber" ou ainda, ironicamente, "universalismo europeu" (ver, respectivamente, as obras de Samir Amin (1994, 2006), Edward Said (2007), Edgardo Lander (2005) e Imannuel Wallerstein (2007)).

O processo histórico de produção destas polaridades está ainda em curso e permeia a produção da sociabilidade contemporânea, inclusive no que tange às dimensões político-epistemológicas. Observase, em primeiro lugar, a reificação e o poder discursivo das ciências, entre as quais se destacam hoje a velha economia e as novas tecnociências da vida, como as únicas expressões de um conhecimento de caráter 
universal; e, em segundo lugar, o impedimento simbólico e concreto a que as chamadas "culturas" sejam alçadas, de fato, a formas de atuação e expressão mais globais e menos restritas, embora reconhecidas em seu valor enquanto "patrimônio da humanidade".

Fica, assim, para a Análise do Discurso, a tarefa de desenvolver a crítica a estas polaridades, a partir seja da vertente marxista de Bakhtin (1990), seja da linha de Pêcheux, seja da exploração da obra lukacsiana. Estas tradições, por sua inscrição em uma perspectiva ontológica de natureza materialista sobre a ideologia e da língua, construíram um caminho para a reflexão crítica sobre este processo discursivo, político e epistemológico instituinte da sociabilidade contemporânea em termos da oposição "trágica" entre universal e diverso - ou entre língua e sujeitofalante.

\section{REFERÊNCIAS}

AMARAL, M. V. B. Ideologia e discurso: aproximações da análise do discurso das teorias de Lukacs e Bakhtin. Signo, v. 33, n. 54, p. 106-119, jan./jun. 2008.

AMIN, S. Las derivas de la modernidad. El caso de África y del mundo árabe. 2006. Disponível em:

<http://bibliotecavirtual.clacso.org.ar/ar/libros/sursur/politica/PICtres1.pdf > . Acesso em: 16 jun. 2011.

. Eurocentrismo: crítica de uma ideologia. Lisboa: Dinossauro, 1994.

AUROUX, S. A filosofia da linguagem. Campinas: Unicamp, 1998.

BAKHTIN, M. (VOLOCHINOV). Marxismo e filosofia da linguagem: problemas fundamentais do método sociológico na Ciência da Linguagem. São Paulo: Hucitec, 1990.

BRAIT, B. Bakhtin e a natureza constitutivamente dialógica da linguagem. In: (Org.). Bakbtin, dialogismo e construção de sentido. Campinas: Editora da Unicamp, 1997. p. 91-102.

BAUMAN, R.; BRIGGS, C. Voices of modernity: language ideologies and the politics of inequality. Cambridge: Cambridge University Press, 2003.

EAGLETON, T. As ilusões do pós-modernismo. Rio de Janeiro: Jorge Zahar, 1998.

Depois da teoria: um olhar sobre os estudos culturais e o pós-

modernismo. Rio de Janeiro: Civilização Brasileira, 2005.

MARTINS - Para uma crítica da economia linguística... 
FLORÊNCIO, A. M. et al. Análise do discurso: fundamento \& prática. Maceió: EDUFAL, 2009.

FLORES, V. Dialogismo e enunciação: elementos para uma epistemologia da linguística. Linguagem \& Ensino, v.1, n.1, p. 3-32, jan./jun. 1998.

FOUCAULT, M. As palavras e as coisas: uma arqueologia das ciências humanas. $8^{\circ}$ ed. São Paulo: Martins Fontes, 1999.

LANDER, E. A colonialidade do saber: eurocentrismo e ciências sociais. Buenos Aires: Clacso, 2005.

LOCKE, J. Ensaio acerca do entendimento humano. In: Os Pensadores. Volume XVIII. São Paulo: Abril, 1973.

MAGALHÃES, B. O sujeito do discurso: um diálogo possível e necessário. Linguagem em (Dis)curso. v. 3, Número Especial, p. 73-90, 2003.

; MARIANI, B. Processos de subjetivação e identificação: ideologia e inconsciente. Linguagem em (Dis)curso, v. 10, n. 2, p. 391-408, maio/ago. 2010. MARX, K.; ENGELS, F. A ideologia alemã. São Paulo: Boitempo, 2007.

ORTIZ, R. $A$ diversidade dos sotaques: o inglês e as ciências sociais. São Paulo: Brasiliense, 2008.

PÊCHEUX, M. Há uma via para a Linguística fora do logicismo e do sociologismo? Escritos 3. Campinas: Labeurb, 1998. p. 5-16.

; GADET, F. A lingua inatingivel: o discurso na história da Linguística. Campinas: Pontes, 2004.

SAID, E. Orientalismo: o Oriente como invenção do Ocidente. São Paulo: Companhia das Letras, 2007.

SWIFT, J. As viagens de Gulliver. São Paulo: Penguin Companhia das Letras, 2010.

WALLERSTEIN, I. O universalismo europeu: a retórica do poder. São Paulo: Boitempo, 2007.

Recebido em: 07/07/11. Aprovado em: 02/06/12. 
Title: A contribution to the critic of linguistic economy: the obliteration of the social ontology of language and of speaker in John Locke

Author: Carla Macedo Martins

Abstract: In this paper the foundation of language and of the subject-speaker in the Essay Concerning Human Understanding, by John Locke, is analyzed. In this work, we discuss the formulation of the notion of language as a universal space, aiming at communication and social functioning, and of the notion of subject-speaker as an individual in control of discourse and as the locus of linguistic change. The opposition is observed between Locke's ontology and the social ontology of language identified by Marx and Engels in The German Ideology. The paper also correlates Locke's foundation of language and of the subject to modern politics and science. Finally, the text links the discussion of ontology of language and of the subject to the contemporary analysis about the dichotomy between scientific universalism and cultural diversity within social sciences and humanities, and the possible contributions of marxist discourse analysis to this debate.

Keywords: Ontology. Epistemology. Historicity. Language. Universalism.

Titulo: Para una crítica de la economía lingüistica: la eliminación de la ontología social de la lengua y del sujeto-hablante a partir de Locke

Autor: Carla Macedo Martins

Resumen: En este ensayo, analisamos la fundación de la lengua y del sujeto-hablante a partir del Ensayo acerca del entendimiento bumano, de John Locke. En esta obra, discutimos la formulación de la noción moderna de lengua como espacio de lo universal, con vistas a la comunicabilidad y funcionalidad, y de la noción de sujeto-hablante como señor del discurso y lócus de transformación lingüistica. Se observa, así, en este pensador, un contrapunto a la ontología social de la lengua identificada en Marx y Engels en la obra La Ideología Alemana. El ensayo correlaciona aun la fundación de la lengua y del sujeto en Locke con la política y la ciencia modernas capitalistas. Por fin, el texto vincula la discusión sobre la ontología de la lengua y del sujeto con los análisis contemporáneos al respecto de la dicotomía entre diversidad cultural y universalismo científico en el ámbito de las ciencias sociales y bumanas, y las posibles contribuciones de los análisis del discurso de inscripción marxista.

Palabras-clave: Ontología. Epistemología. Historicidad. Lengua. Universalismo.

MARTINS - Para uma crítica da economia linguística... 